\title{
MOLECULAR DYNAMICS ANALYSIS OF WATER ADSORPTION ON CALCIUM SILICATE HYDRATE
}

\author{
JIAHUI DONG*, " YANG WANG**, YI YANG***, RUI GAO** \\ *Yang Ling Vocational and Technical College, Yangling 712100, PR China \\ ** Northwest A\&F University, Yangling 712100, PR China \\ ***Jiangnan University, Wuxi 214122, PR China \\ ${ }^{\#}$ E-mail: 1527wangyang@nwafu.edu.cn
}

Submitted November 18, 2020; accepted January 5, 2021

\begin{abstract}
Keywords: C-S-H, C/S ratio, Water adsorption, Molecular dynamics
Calcium silicate hydrate $(C-S-H)$, as the main product of cement hydration, has an important influence on the cement's structure and properties. In this study, the molecular dynamics method was used to simulate the adsorption process of water molecules on $C-S-H$. The chemical bond and chemical formula structure of the $C-S-H$ model were analysed. The adsorption characteristics of the water molecules on the $C-S-H$ and the influence of water molecules on the structure of the $C-S-H$ were investigated when the calcium-silicon $(C / S)$ ratio range was $0.67-1.67$. The results show that the $C / S$ ratio has a great influence on the adsorption of the $C-S-H$. When the $C / S$ ratio $>1$, the maximum number of adsorbed water molecules increased with an increase in the $C / S$ ratio, but decreased when the $C / S$ ratio $<1$. This law was related to the degree of the charge balance of the $C-S-H$. The $C / S$ ratio has little effect on the adsorption rate of the water molecules. The molecular dynamics behaviour of the $C-S-H$ was analysed on an atomic scale, which laid the foundation for selecting cement-based materials with an optimal C/S ratio in practical engineering.
\end{abstract}

\section{INTRODUCTION}

Calcium silicate hydrate is the main chemical product after cement hydration, resulting from chemical reactions between the interstitial solution of the silicon and calcium hydroxide and the calcium salt and the alkaline silicate solution [1], which account for about $70 \%$ of all hydration products [2]. The interaction of $\mathrm{C}-\mathrm{S}-\mathrm{H}$ with water is a key core characteristic of cementbased material properties, especially on a nanoscale, such as drying and self-shrinkage, thermal expansion, and the cement hydration processes [3]. At the same time, the water molecules invading the silicate chain are also affected by the hydrophilicity and hydrophobicity of the silicate surface [4,5]. Smalkys G et al. [6] synthesised $\mathrm{C}-\mathrm{S}-\mathrm{H}$ through experiments and found that there were two peaks, indicating that the $\mathrm{C}-\mathrm{S}-\mathrm{H}$ was composed of two phases: C-S-H (I) and C-S-H (II). Hou et al. [7] simulated the migration of water molecules between the layers of the $\mathrm{C}-\mathrm{S}-\mathrm{H}$ by the molecular dynamics method, and studied the molecular structure, dynamic movement and the interaction between the water and the surface of the $\mathrm{C}-\mathrm{S}-\mathrm{H}$. The structure and dynamic behaviour of water molecules in the nano-pores were characterised by the density distribution diagram, atomic trajectory, diffusion coefficient and hydrogen bond network, and then the effects of the $\mathrm{C} / \mathrm{S}$ ratio of $1.3-2.0$ and different water contents on the mechanical properties of the $\mathrm{C}-\mathrm{S}-\mathrm{H}$ were simulated by the molecular dynamics method [8].
Tulio Honorio [3] applied the Grand Canonical Monte Carlo Method (GCMC) to study the interaction between the $\mathrm{C}-\mathrm{S}-\mathrm{H}$ nanocrystalline layers when $\mathrm{C} / \mathrm{S}=1$, and analysed the influence of temperature, chemical potential and pressure on the nanocrystalline layer of the $\mathrm{C}-\mathrm{S}-\mathrm{H}$. Bonnaud $[9,10]$ studied the adsorption rule of the water interlayer of the $\mathrm{C}-\mathrm{S}-\mathrm{H}$ under different humidity conditions, and the results showed that the aggregation property of $\mathrm{C}-\mathrm{S}-\mathrm{H}$ decreased with an increase in the interlayer water adsorption. Tong et al. [11] studied the adsorption characteristics of the interlayer water molecules of the $\mathrm{C}-\mathrm{S}-\mathrm{H}$ at different temperatures when $\mathrm{C} / \mathrm{S}=1.67$, and put forward the calculation formula of the adsorption amount of the water molecules on the $\mathrm{C}-\mathrm{S}-\mathrm{H}$ within a certain temperature range, providing a theoretical basis for the calculation of the interlayer water content at a certain temperature. Huang et al. [12] constructed models with $\mathrm{C} / \mathrm{S}$ ratios of $0.67,0.75$, 0.83 and 1 , and used a Compass field to analyse the mechanical properties and behaviours of the $\mathrm{C}-\mathrm{S}-\mathrm{H}$ under axial tensile and compressive stresses at different $\mathrm{C} / \mathrm{S}$ scales on an atomic scale. Although scholars have made a large number of studies on the adsorption and migration rule of the water interlayer of $\mathrm{C}-\mathrm{S}-\mathrm{H}$ on a nanoscale and conducted in-depth analyses on the mechanical properties of $\mathrm{C}-\mathrm{S}-\mathrm{H}$ at different $\mathrm{C} / \mathrm{S}$ ratios, research on the influence of different $\mathrm{C} / \mathrm{S}$ ratios on the interlayer water adsorption characteristics of $\mathrm{C}-\mathrm{S}-\mathrm{H}$ is not sufficient. 
In this study, the interlayer water adsorption characteristics of $\mathrm{C}-\mathrm{S}-\mathrm{H}$ with $\mathrm{C} / \mathrm{S}$ ratios of $0.67,0.83,1$, 1.5 and 1.67 were studied by the molecular dynamics method. The molecular dynamic behaviours of the water adsorption on the $\mathrm{C}-\mathrm{S}-\mathrm{H}$ were characterised by the chemical bond analysis, chemical formula structure analysis, adsorption isotherm, and mean square displacement (MSD).

\section{THEORETICAL}

Model construction

The Tobermorit $11 \AA$ obtained by Hamid et al. [13] was selected as the initial model, and the size of the simulated box is as follows: $a=6.69 \AA, b=7.39 \AA$, $c=22.77 \AA, \alpha=90^{\circ}, \beta=90^{\circ}, \gamma=123.49^{\circ}$. The model is shown in Figure 1a.

At present, there are a lack of unified standards for molecular dynamics modelling and parameter settings [14]. According to Bonnaud's suggestion [9], there was no $\mathrm{OH}$ group added in the $\mathrm{C}-\mathrm{S}-\mathrm{H}$ unit cell, and the $\mathrm{H}_{2} \mathrm{O}$ and $\mathrm{H}$ atoms in the model were deleted, then the initial model was expanded to a $4 * 3 * 1$ supercell. The models with different $\mathrm{C} / \mathrm{S}$ ratios were obtained by randomly deleting the bridging $\mathrm{Si}-\mathrm{O}$ bonds. Qn is used to represent the polymerisation degree of the silicon chain. It should ensure that the mean silicate chain length and the Qn distribution of the $\mathrm{C}-\mathrm{S}-\mathrm{H}$ structure are consistent with the nuclear magnetic resonance spectroscopy (NMR) results [15]. The monoclinic cell structure was converted into an orthogonal structure [16], and the $\mathrm{C}-\mathrm{S}-\mathrm{H}$ initial configuration with $\mathrm{C} / \mathrm{S}$ ratios of $0.67,0.83,1.0,1.5$ and 1.67 was obtained, as shown in Figure $1 \mathrm{~b}$ (taking $\mathrm{C} / \mathrm{S}=1.67$ as an example). The $\mathrm{Z}$-axis direction is the stacking direction of the calcium-silicon layer, the Y-axis direction is the connection direction of the silicon chain, and the $\mathrm{X}$-axis direction is the direction perpendicular to the connection direction of the silicon chain within the calcium-silicon layer. Table 1 shows the $\mathrm{Q}_{n}$ distribution of the silicon chains in the different $\mathrm{C} / \mathrm{S}$ ratios.

As can be seen from Table 1, with an increase in the $\mathrm{C} / \mathrm{S}$ ratio, the average length of the silicon chain decreases, that is, the proportion of $\mathrm{Q}_{2}$ decreases and the proportion of $\mathrm{Q}_{1}$ increases, which leads to more defects in the silicon chains. The polymerisation degree of the silicon chain of the model established in this paper is consistent with that in the literature [8], which proves the reliability of the established model.

Table 1. $\mathrm{Q}_{n}$ distribution of silicon chain in different $\mathrm{C} / \mathrm{S}$ ratios.

\begin{tabular}{lccc}
\hline $\begin{array}{c}\mathrm{C} / \mathrm{S} \\
\text { ratios }\end{array}$ & $\begin{array}{c}\mathrm{Q}_{0} \text { content } \\
(\%)\end{array}$ & $\begin{array}{c}\mathrm{Q}_{1} \text { content } \\
(\%)\end{array}$ & $\begin{array}{c}\mathrm{Q}_{2} \text { content } \\
(\%)\end{array}$ \\
\hline 0.67 & - & - & $\begin{array}{c}\text { almost all } \\
\text { long chains }\end{array}$ \\
\hline 0.83 & - & 30.4 & 69.6 \\
\hline 1 & 21.0 & 33.0 & 46.0 \\
\hline 1.5 & 4.2 & 58.3 & 37.5 \\
\hline 1.67 & 8.14 & 67.44 & 24.42 \\
\hline
\end{tabular}

Force field

The commonly used force fields for cement materials include ClayFF, IFF, CementFF, ReaxFF, and CSHFF. According to the characteristics of each force field [17], ClayFF field is selected to describe the $\mathrm{C}-\mathrm{S}-\mathrm{H}$ in this paper. Calcium atoms are divided into interlayer calcium atoms and intralayer calcium atoms, while oxygen atoms on the silicon chain are divided into two types: those connected to two silicon atoms are bridging oxygen atoms, and those connected to one silicon atom are non-bridging oxygen atoms. In this study, interlayer calcium atoms, intra-layer calcium atoms, bridging oxygen atoms and non-bridging oxygen atoms are respectively represented by $\mathrm{Cah}, \mathrm{Cao}, \mathrm{Ob}$ and Obos. In previous studies, a ClayFF field has been successfully

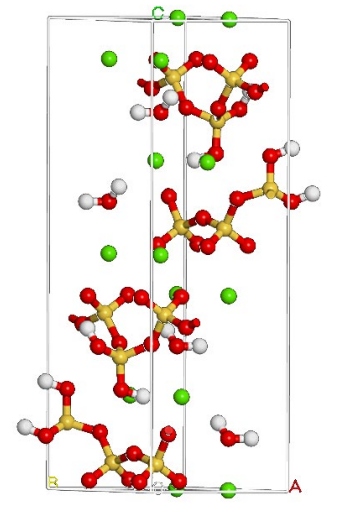

a) Tobermorit $11 \AA$ initial model structure diagram

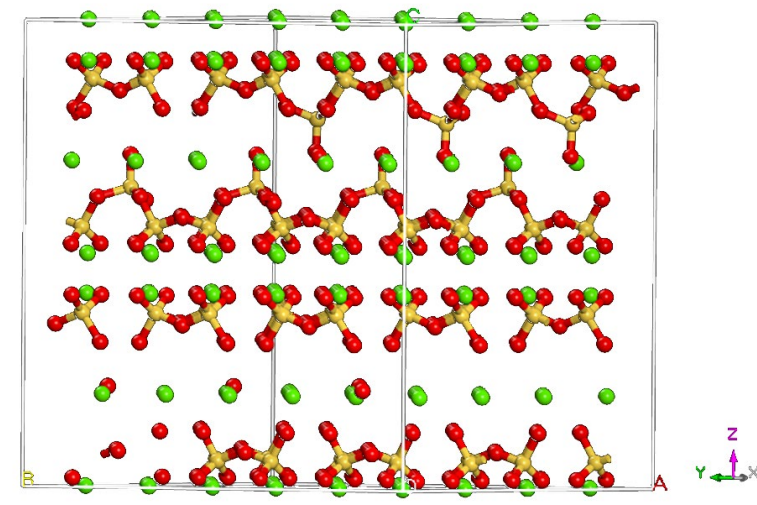

b) $\mathrm{C} / \mathrm{S}=1.67 \mathrm{C}-\mathrm{S}-\mathrm{H}$ model

Figure 1. The red and yellow sticks are the silicate chains; the green balls are calcium atoms; the red balls are oxygen atoms; the yellow balls are silicon atoms. 
used to simulate the structure of the oxide and hydroxide materials, the behaviour of water and ions in clay, the layered structural phases, the cement hydrate, and the multi-component mineral systems [18-22]. In this study, the boundary conditions were simulated as periodic, what is more, the cut-off radius of the coulomb interaction was $10 \AA$, and the cut-off radius of the Lennard-Jones (12-6) potential was $8 \AA$. The GCMC method was used by setting the equilibrium step number as $8 \cdot 10^{6}$, and the production step number as $8 \cdot 10^{7}$. The adsorption process of $\mathrm{C}-\mathrm{S}-\mathrm{H}$ on water molecules was completed at $298 \mathrm{~K}$, and the water molecular model used the SPC model [23], the chemical potential of the water molecule was fixed to the standard state $\left(298 \mathrm{~K}, 1 \mathrm{~g} \cdot \mathrm{cm}^{-3}\right)$, and the harmonic potential field was used to represent the tension of the $\mathrm{O}-\mathrm{H}$ bond and the bending of the $\mathrm{H}-\mathrm{O}-\mathrm{H}$ Angle in the water molecule. The process of adsorbing water molecules is shown in Figure 2 (take $\mathrm{C} / \mathrm{S}=1.67$ as an example). A ClayFF field was used to calculate the optimal energy of the model and achieve a structural balance under the NPT (Nosé-Parrinello-Rahman) ensemble. The ClayFF field parameters are shown in literature [24].

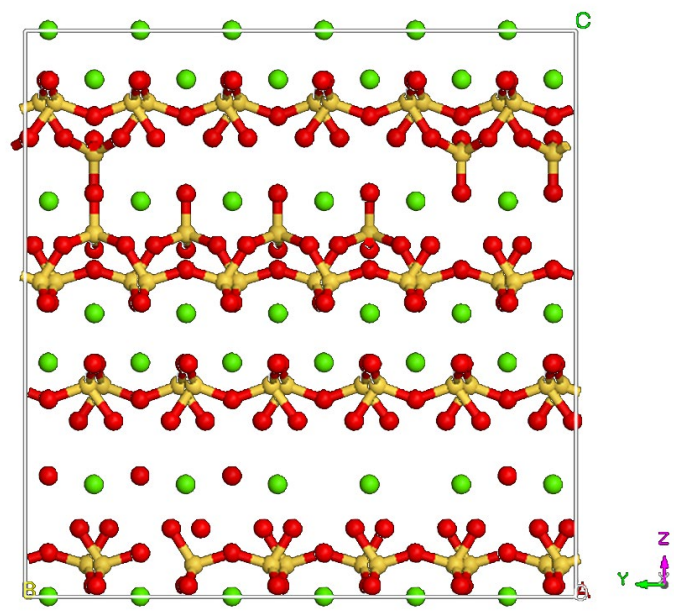

a) $\mathrm{C}-\mathrm{S}-\mathrm{H}$ model without water

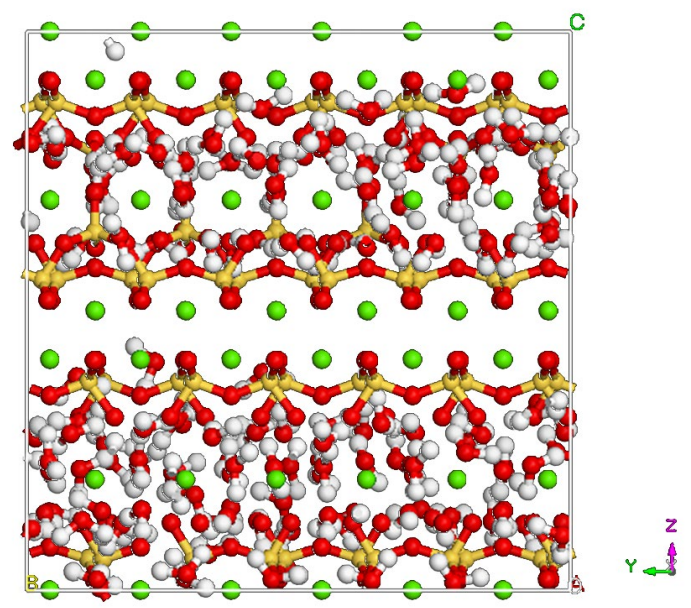

b) The $\mathrm{C}-\mathrm{S}-\mathrm{H}$ model after adsorbing water molecules

Figure 2. C-S-H adsorption of water molecules.

\section{RESULTS AND DISCUSSIONS}

Chemical bond analysis

The GCMC method was used to simulate the adsorption process of the $\mathrm{C}-\mathrm{S}-\mathrm{H}$ on the water molecules under different $\mathrm{C} / \mathrm{S}$ ratios. Figure 3 shows the probability density of various bond lengths after $\mathrm{C}-\mathrm{S}-\mathrm{H}$ adsorbs the water molecules under a saturated vapour pressure when $\mathrm{C} / \mathrm{S}=1.67$. As can be seen from Figure 3, the length of the $\mathrm{O}-\mathrm{H}$ bond is about $1.1 \AA$, and the length of the $\mathrm{Si}-\mathrm{Oh}$ bond is about $1.58 \AA$. As for the $\mathrm{Si}-\mathrm{Obos}$ bond, it is about $1.72 \AA$, and the length of the $\mathrm{Si}-\mathrm{Ob}$ bond is about $1.78 \AA$. The difference in the bond length is due to the fact that the oxygen atoms $\left(\mathrm{O}^{*}\right)$ and non-bridging oxygen atoms (Obos) and oxygen atoms $(\mathrm{Ob})$ in water have different charges, and $\mathrm{O}^{*}$ have the least charges. The other side of $\mathrm{Si}-\mathrm{Oh}$ bond is connected to the $\mathrm{H}$ atoms only, and hydroxyl groups are more likely to be attracted to $\mathrm{Si}$ atoms, so the $\mathrm{Si}-\mathrm{Oh}$ bond is the shortest. $\mathrm{Ob}$ atom is connected to two $\mathrm{Si}$ atoms and simultaneously attracted from different $\mathrm{Si}$ atoms, so the $\mathrm{Si}-\mathrm{Ob}$ bond is the longest. This is very close to the average $\mathrm{Si}-\mathrm{O}$ bond length of $1.641 \AA$ simulated by Zhou [25] at room temperature and $1.64 \AA$ obtained by the experiment [26]. The fluctuation peak between the $\mathrm{Si}-\mathrm{O}$ bonds is due to the slight change in the $\mathrm{Si}-\mathrm{O}$ bond length of $\mathrm{C}-\mathrm{S}-\mathrm{H}$ after adsorption of the water molecules after the energy minimisation.

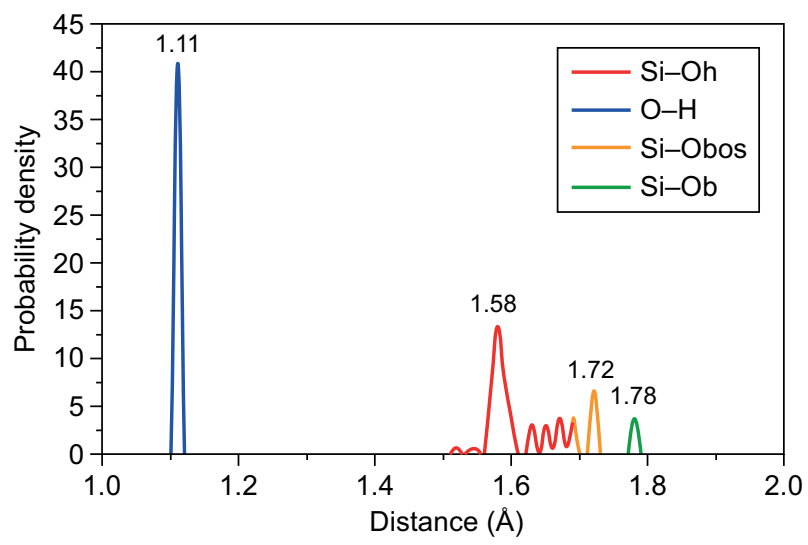

Figure 3. Probability density of the $\mathrm{C}-\mathrm{S}-\mathrm{H}$ bond length.

Chemical formula structure analysis

In order to better understand the structural changes of $\mathrm{C}-\mathrm{S}-\mathrm{H}$ after the adsorption of water molecules, the fraction of vacant sites $\alpha$ and the charge balance extent $\beta$ were introduced [27], as shown in Equations 1 and 2.

$$
\begin{gathered}
\alpha=\frac{1}{1+M C L} \\
\beta=6\left[1-(1-\alpha)^{n}\right]
\end{gathered}
$$

where $M C L$ is the average silicon chain length, and $n$ is the $\mathrm{C} / \mathrm{S}$ ratio. The value range of $\alpha$ is $0 \sim 2$ [28], beyond this range, it is 0 or 2 . 
According to the $\mathrm{Q}_{n}$ distribution in Table 1 and combined with Equation 1 and (2), $\alpha$ and $\beta$ under different $\mathrm{C} / \mathrm{S}$ ratios can be obtained, as shown in Figure 4.

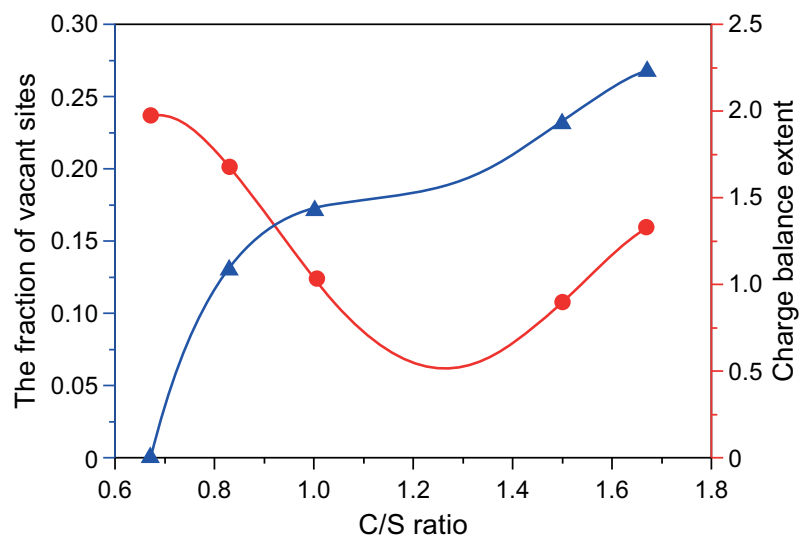

Figure 4. Structural changes of the $\mathrm{C}-\mathrm{S}-\mathrm{H}$ under different $\mathrm{C} / \mathrm{S}$ ratios.

It can be seen from Figure 4 that with an increase in the $\mathrm{C} / \mathrm{S}$ ratio, the fraction of vacant site increases, especially when the $\mathrm{C} / \mathrm{S}$ ratio $<1$, it increases significantly. The simulation results are consistent with the results obtained by Sylvain Grangeon et al. [29] who used ${ }^{29} \mathrm{Si}$ NMR, which again proves the reliability of the simulation results. At the same time, as the $\mathrm{C} / \mathrm{S}$ ratio increases, the absolute value of the charge balance extent first decreases and then increases.

\section{Law of water adsorption}

In order to explore the influence of the $\mathrm{C} / \mathrm{S}$ ratio on the adsorption capacity of the water molecules, the GCMC method was used to simulate the number of water molecules adsorbed by the $\mathrm{C}-\mathrm{S}-\mathrm{H}$ when the $\mathrm{C} / \mathrm{S}$ ratio was $0.67,0.83,1,1.5,1.67$. The adsorption results are shown in Figure 5.

It can be seen from Figure 5 that when $\mathrm{C} / \mathrm{S}>1$, the number of adsorbed water molecules increases with an increase in the $\mathrm{C} / \mathrm{S}$ ratio under the same pressure, this is due

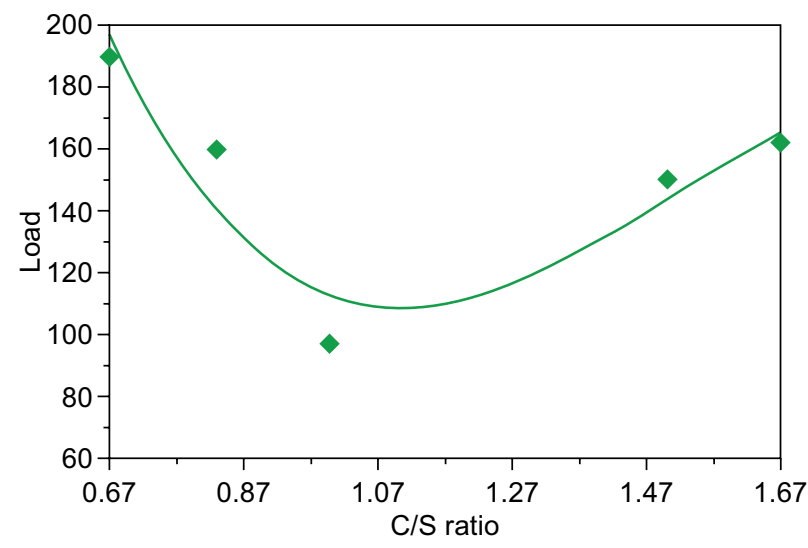

Figure 5. Number of adsorbed water molecules with the different $\mathrm{C} / \mathrm{S}$ ratios. to the number of $\mathrm{Ca}$ atoms that are unchanged, the larger the $\mathrm{C} / \mathrm{S}$ ratio is, the more $\mathrm{Si}$ atoms need to be deleted, the more defects in the silicon chains, the larger the space. More water molecules will be embedded in the defective silicate chains, which will also lead to the rearrangement of the interlayer calcium atoms and spread to the nonbridging sites of the defective silicate chains. When $\mathrm{C} / \mathrm{S}<1$, it is found that, at the same pressure, the number of adsorbed water molecules decreases with an increase in the $\mathrm{C} / \mathrm{S}$ ratio, which is consistent with the experimental results [29]. In order to ensure the maximum density of the $\mathrm{C}-\mathrm{S}-\mathrm{H}$, the number of $\mathrm{Si}$ atoms was kept certain when the model was created, and part of the free $\mathrm{Ca}$ atoms were deleted. To ensure the chemical formula and charge balance, parts of $\mathrm{O}$ atoms were deleted, leading to some defective silicon chains. Water molecules not only diffused to the defect in the silicon chains, but also to the defect in the calcium-silicon atoms in the layer, and then diffused between the layers, so the number of adsorbed water molecules increased. Interestingly, with a change in the $\mathrm{C} / \mathrm{S}$ ratio, the change rule of the absolute value of the charge balance extent is basically consistent with that of the adsorptive capacity of the water molecules, which is most likely that the charge affects the adsorption capacity of the $\mathrm{C}-\mathrm{S}-\mathrm{H}$ to the water molecules to a certain extent.

The adsorption isotherms of the $\mathrm{C}-\mathrm{S}-\mathrm{H}$ with the $\mathrm{C} / \mathrm{S}$ ratio of $0.67,0.83,1,1.5$ and 1.67 were simulated, as shown in Figure 6.

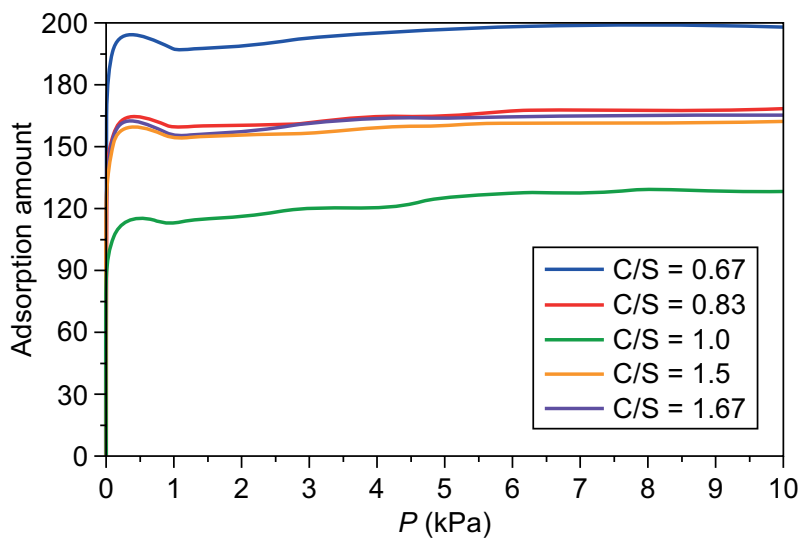

Figure 6. Adsorption isotherms of the water molecules by $\mathrm{C}-\mathrm{S}-\mathrm{H}$ under different $\mathrm{C} / \mathrm{S}$ ratios.

As can be seen from Figure 6, when the pressure is small, the adsorption capacity linearly increases, as the pressure increases, the adsorption capacity gradually flattens out. The adsorption curve conforms to the characteristics of the Langmuir adsorption isotherm [30]. In addition, the $\mathrm{C} / \mathrm{S}$ ratio has a great influence on the adsorption capacity of the water molecules. When $\mathrm{C} / \mathrm{S}=$ $=0.67$, the number of adsorbed water molecules was the largest, and when $\mathrm{C} / \mathrm{S}=1$, the number of adsorbed water molecules was the smallest. The adsorption law is consistent with that in Figure 5. Moreover, from the 
change rate of the adsorption capacity, the change in the $\mathrm{C} / \mathrm{S}$ ratio has little effect on the adsorbed water molecular rate of the $\mathrm{C}-\mathrm{S}-\mathrm{H}$.

\section{MSD}

MSD is the main parameter to describe molecular dynamics. The expression of MSD is shown in Equation 3.

$$
M S D_{t}=\left\langle\left|r_{i}(t)-r_{i}(0)\right|^{2}\right\rangle
$$

where $r_{i}(t)$ represents the position of atom $i$ at $t$ time, and $r_{i}(0)$ represents the initial position of atom $i$.

The greater the MSD value at time $t$, the farther atom $i$ is from the initial position, the faster the atomic diffusion rate. The comparison diagrams of various kinds of atomic diffusion at different $\mathrm{C} / \mathrm{S}$ ratios are shown in Figure 7.

As can be seen from Figure 7, the $\mathrm{H}$ atoms and $\mathrm{O}$ atoms in the water molecules have the fastest diffusion rate, and the diffusion rate of the $\mathrm{H}$ atoms is higher than $\mathrm{O}$ atoms. As a result, some $\mathrm{O}$ atoms in the water molecules connected to the $\mathrm{Si}$ atoms to form covalent bonds, the diffusion of $\mathrm{O}$ atoms was limited to a certain

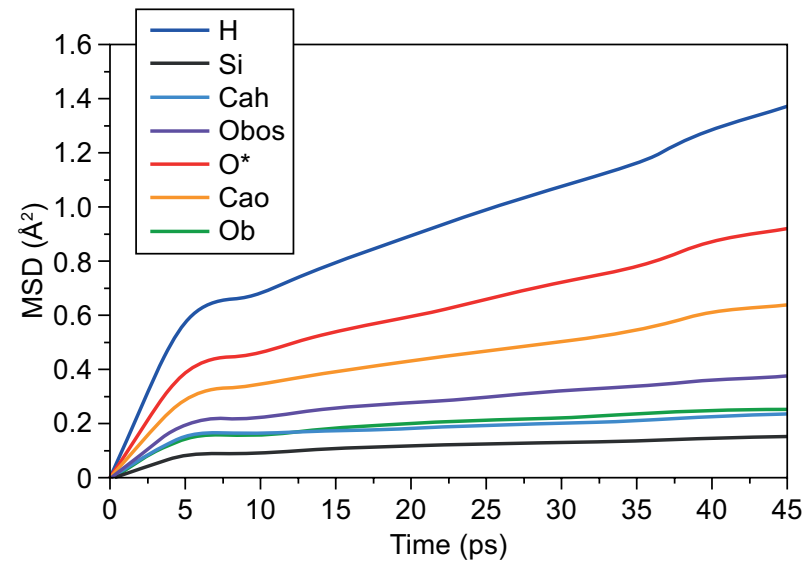

a) $\mathrm{C} / \mathrm{S}=1.67$

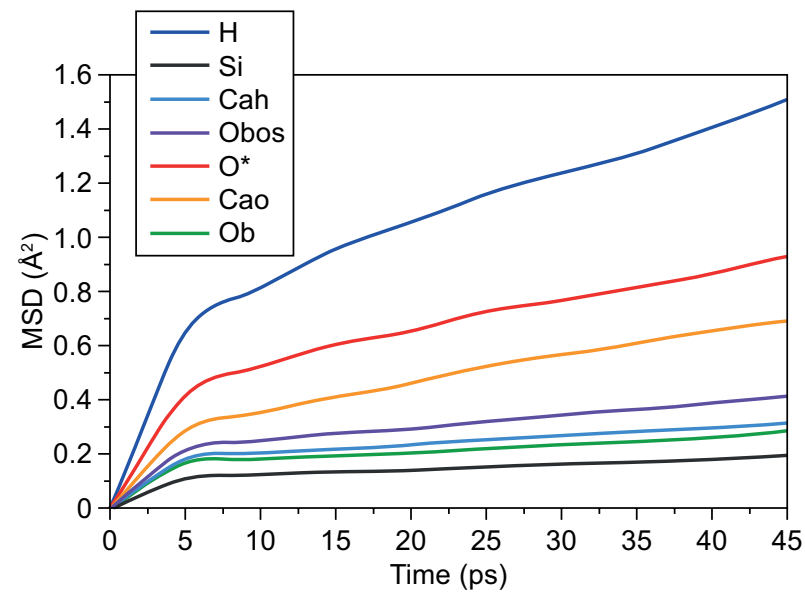

b) $\mathrm{C} / \mathrm{S}=1.5$ extent. The diffusion rate of the interlayer calcium atoms (Cao) was significantly higher than that of intracellular calcium atoms (Cah). This is due to the fact that the water molecules were first embedded in the defects of the $\mathrm{Ca}$ and $\mathrm{Si}$ atoms, which weakened the interaction between the $\mathrm{Ca}$ atoms and the $\mathrm{O}$ atoms in the silicon chains, so the diffusion rate was increased to a certain extent. The diffusion rate of the $\mathrm{Ca}$ atoms was slightly higher than that of
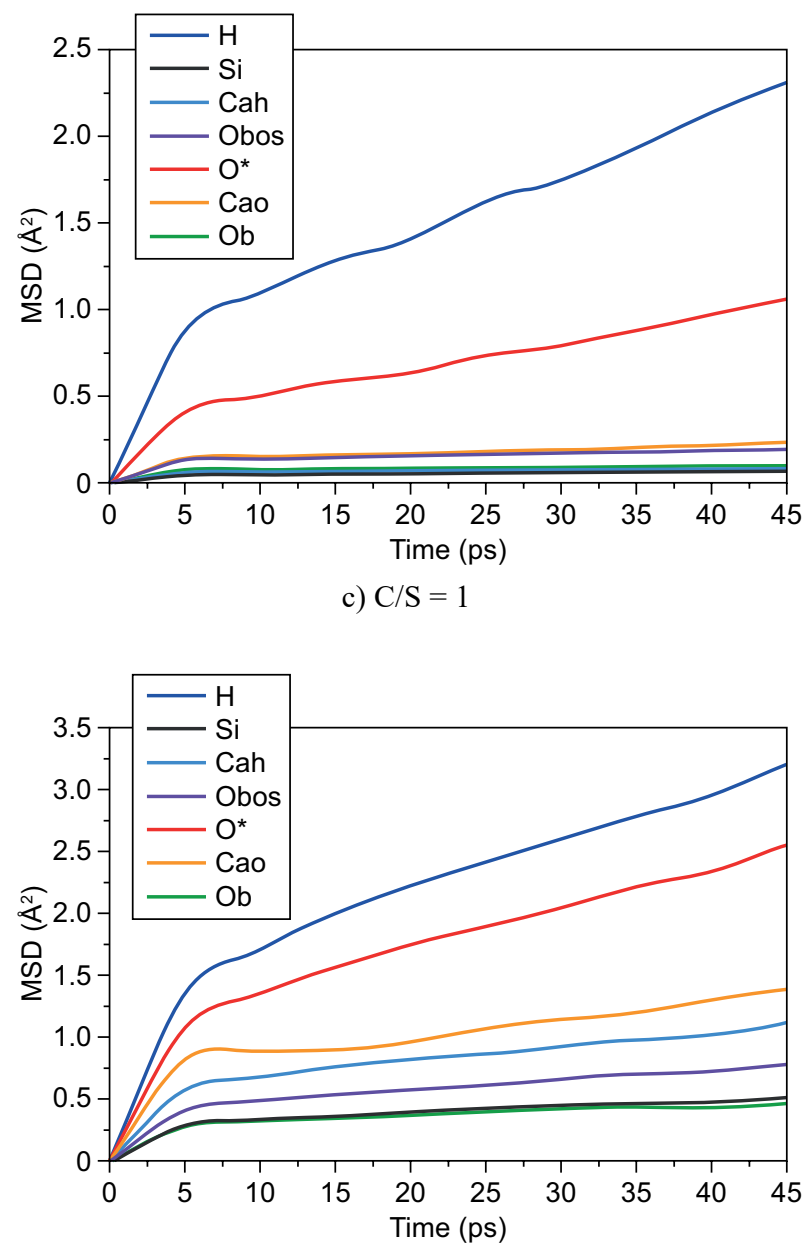

d) $\mathrm{C} / \mathrm{S}=0.83$

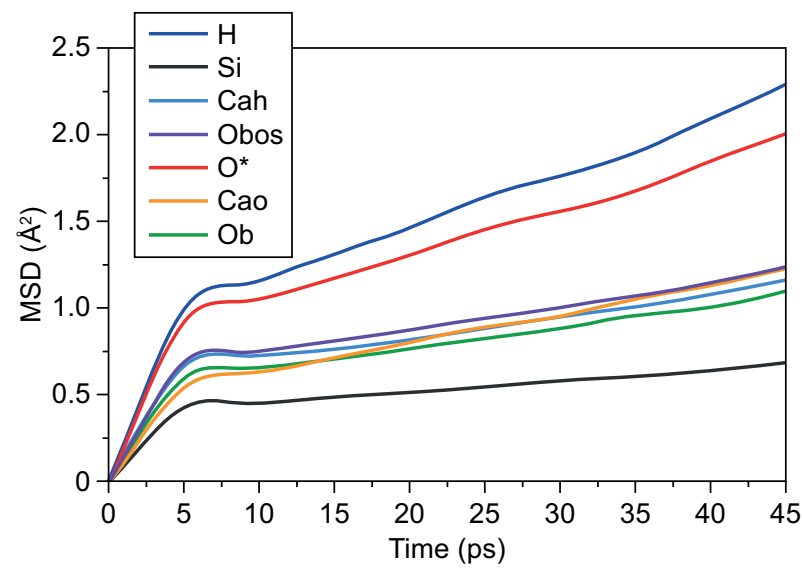

e) $\mathrm{C} / \mathrm{S}=0.67$

Figure 7. MSD of the atoms under different $\mathrm{C} / \mathrm{S}$ ratios. 
bridged oxygen atoms $(\mathrm{Ob})$ and the non-bridged oxygen atoms (Obos), thus the Obos atoms in the $\mathrm{C}-\mathrm{S}-\mathrm{H}$ can effectively adsorb the $\mathrm{Ca}$ atoms. Moreover, the $\mathrm{Si}$ atoms in the silicon layer have the lowest diffusion rate.

Figures 8 and 9 show the diffusion rates of the $\mathrm{H}$ atoms and $\mathrm{O}$ atoms at different $\mathrm{C} / \mathrm{S}$ ratios. It can be seen from the figures that the $\mathrm{H}$ atoms and $\mathrm{O}$ atoms have the same law of diffusion at different $\mathrm{C} / \mathrm{S}$ ratios, and during

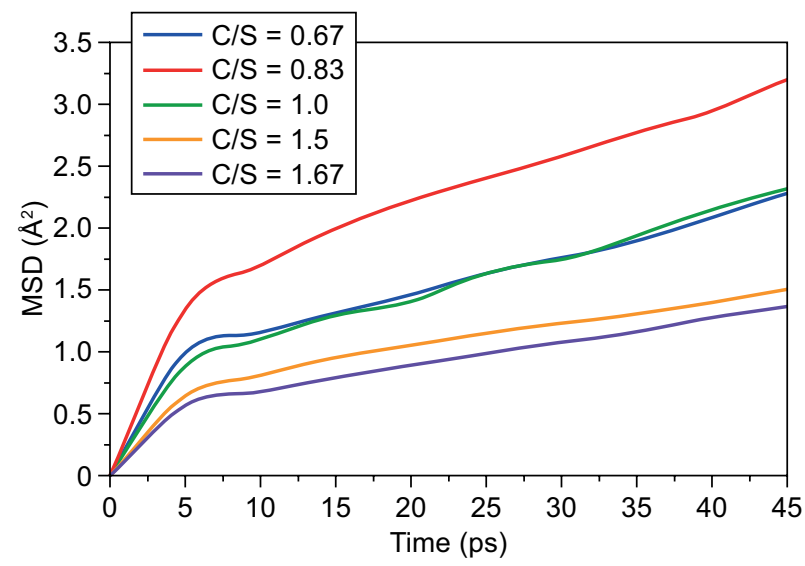

Figure 8. MSD comparison of the $\mathrm{H}$ atoms under different $\mathrm{C} / \mathrm{S}$ ratios.

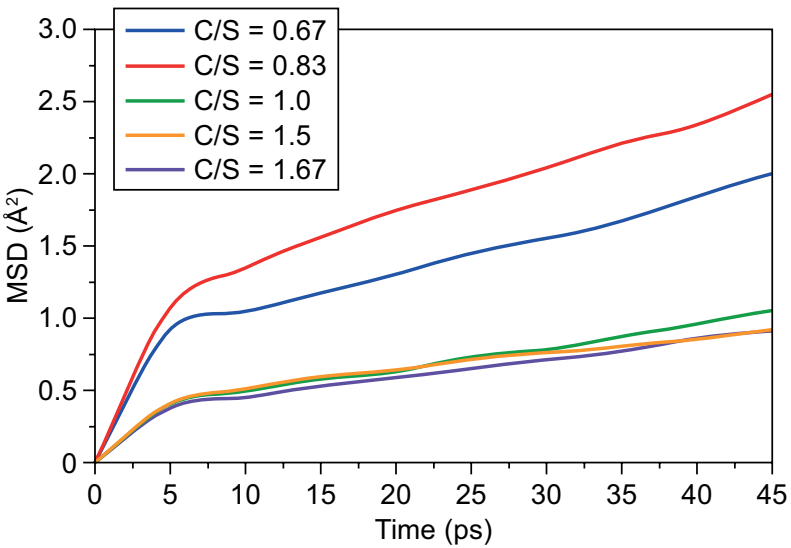

Figure 9. MSD comparison of the $\mathrm{O}^{*}$ atoms under different $\mathrm{C} / \mathrm{S}$ ratios.

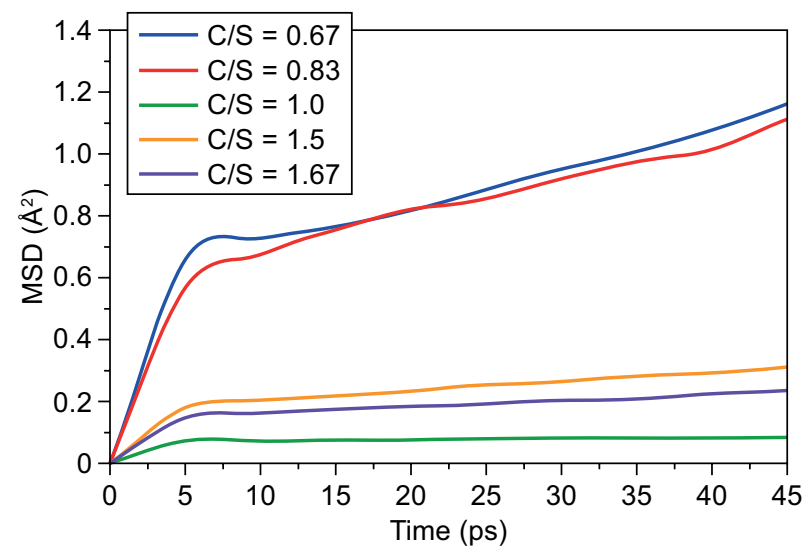

Figure 10. MSD comparison of the $\mathrm{Ca}$ atoms at different $\mathrm{C} / \mathrm{S}$ ratios. the first $5 \mathrm{ps}$, the MSD is approximately linear with time, which indicates that the diffusion rate of the $\mathrm{H}$ and $\mathrm{O}$ atoms was very fast, and then the diffusion rate gradually decreased until reaching an equilibrium state. Dr. Zhou [31] defined five kinds of water molecules at different positions in the system, and the water molecules have different diffusion laws. The results in this paper are consistent with the diffusion laws of the water molecules in the channel region. With an increase in the $\mathrm{C} / \mathrm{S}$ ratio, more $\mathrm{Si}-\mathrm{O}$ bonds are deleted and more Obos bonds are released. These Obos bonds from defective silicon chains which can form a strong H-bond attraction with the water molecules, thus reducing the activity of the water molecules.

Figure 10 shows the MSD of the $\mathrm{Ca}$ atoms at different $\mathrm{C} / \mathrm{S}$ ratios. When $\mathrm{C} / \mathrm{S}=0.67$, MSD reaches the maximum, followed by $\mathrm{C} / \mathrm{S}=0.83$, and when $\mathrm{C} / \mathrm{S}=1$, MSD reaches the minimum. The variation in the MSD for the $\mathrm{Ca}$ atoms is consistent with that of the $\mathrm{C}-\mathrm{S}-\mathrm{H}$ adsorbed water at the different $\mathrm{C} / \mathrm{S}$ ratios. This is due to the high diffusion of water molecules, which enhances the activity of the $\mathrm{Ca}$ atoms.

\section{CONCLUSIONS}

The $\mathrm{C}-\mathrm{S}-\mathrm{H}$ models with $\mathrm{C} / \mathrm{S}$ ratios of $0.67,0.83,1$, 1.5 and 1.67 were constructed based on the Tobermorit $11 \AA$ model in this study. The adsorption process of the $\mathrm{C}-\mathrm{S}-\mathrm{H}$ on the water molecules was simulated. The molecular dynamic behaviours of the $\mathrm{C}-\mathrm{S}-\mathrm{H}$ under different $\mathrm{C} / \mathrm{S}$ ratios were analysed on an atomic scale by analysing the chemical bond, chemical formula structure, adsorption isotherm and MSD. Based on the simulation results obtained in this study, the following conclusions are drawn:

- The fraction of vacant sites increases with an increase in the $\mathrm{C} / \mathrm{S}$ ratio, and the increased speed is obvious when $\mathrm{C} / \mathrm{S}<1$. The absolute value of the charge balance extent first decreases and then increases.

- The $\mathrm{C} / \mathrm{S}$ ratio has a great influence on the hydration performance of the $\mathrm{C}-\mathrm{S}-\mathrm{H}$ structure. When $\mathrm{C} / \mathrm{S}>1$, the number of adsorbed water molecules increases with an increase in the $\mathrm{C} / \mathrm{S}$ ratio; when $\mathrm{C} / \mathrm{S}<1$, the number of adsorbed water molecules decreases with an increase in the $\mathrm{C} / \mathrm{S}$ ratio at the same pressure, which is basically consistent with the change rule of the absolute value of the charge balance extent. Therefore, it is speculated that charge balance extent will affect the adsorption characteristics of the $\mathrm{C}-\mathrm{S}-\mathrm{H}$ for the water molecules to a certain extent. The $\mathrm{C} / \mathrm{S}$ ratio has little effect on the adsorption rate of the $\mathrm{C}-\mathrm{S}-\mathrm{H}$.

- The diffusion rate of the $\mathrm{H}$ atoms is the fastest, followed by the $\mathrm{O}$ atoms for the $\mathrm{C}-\mathrm{S}-\mathrm{H}$ after the water adsorption. The diffusion rate of the interlayer $\mathrm{Ca}$ atoms (Cao) is significantly higher than that of 
the intralayer $\mathrm{Ca}$ atoms (Cah). What is more, the diffusion rate of the calcium atoms is slightly higher than that of the bridged oxygen atoms $(\mathrm{Ob})$ and non-bridged oxygen atoms (Obos), while that of the $\mathrm{Si}$ atoms is the slowest. With an increase in the $\mathrm{C} / \mathrm{S}$ ratio, the atomic diffusion rate basically decreases.

\section{Acknowledgements}

This research was funded by the Cernet Innovation Project (NGII20190624).

\section{REFERENCES}

1. Allen A., Thomas J., Jennings H. (2007): Composition and density of nanoscale calcium-silicate-hydrate in cement. Nature Materials, 6(4), 311-316. doi: 10.1038/nmat1871

2. Jia Y., Zhao T., Hou D. (2019): Molecular dynamics study on transport of water and ions in nanometer channel of $\mathrm{C}-\mathrm{S}-\mathrm{H}$ unsaturated and saturated state. Bulletin of The Chinese Ceramic Society, 38(3), 615-621.

3. Honorio T. (2019): Monte carlo molecular modeling of temperature and pressure effects on the interactions between crystalline calcium silicate hydrate layers. Langmuir, 35(11), 3907-3916. doi: 10.1021/acs.langmuir.8b04156

4. Lee S., Rossky P. (1994): A comparison of the structure and dynamics of liquid water at hydrophobic and hydrophilic surfaces-a molecular dynamics simulation study. Journal of Chemical Physics,100(4), 3334-3345. doi: 10.1063/ 1.466425

5. Giovambattista N., Rossky P., Debenedetti P. (2009): Effect of temperature on the structure and phase behavior of water confined by hydrophobic,hydrophilic, and heterogeneous surfaces. Journal of Physical Chemistry B, 113(42), 13723-13734. doi:10.1021/jp9018266

6. Smalakys G. (2020): The hydrothermal synthesis of $1.13 \mathrm{~nm}$ tobermorite from granite sawing powder waste. Ceramics Silikaty, 64(3), 239-248. doi: 10.13168/cs.2020.0013

7. Hou D., Li Z. (2014): Molecular dynamics study of water and ions transport in nano-pore of layered structure: A case study of tobermorite. Microporous \& Mesoporous Materials, 195, 9-20. doi: 10.1016/j.micromeso.2014.04.011

8. Hou D., Li H., Zhang L., et al. (2018): Nano-scale mechanical properties investigation of $\mathrm{C}-\mathrm{S}-\mathrm{H}$ from hydrated tri-calcium silicate by nano-indentation and molecular dynamics simulation. Construction and Building Materials, 189(20), 265-275.doi:10.1016/j.conbuildmat.2018.08.215

9. Bonnaud P., Ji Q., Coasne B., et al. (2012): Thermodynamics of water confined in porous calcium-silicate-hydrates. Langmuir, 28(31), 11422-11432. doi: 10.1021/la301738p

10. Bonnaud P., Ji Q., Vliet K. (2013): Effects of elevated temperature on the structure and properties of calcium-silicate-hydrate gels: the role of confined water. Soft Matter, 9(28), 6418-6429. doi: 10.1039/c3sm50975c

11. Tong T., Li Z. (2020): Adsorption law of interlayer water of $\mathrm{C}-\mathrm{S}-\mathrm{H}$ and its effect on the molecular structure. Material Reports, 34(16), 16049-16054. doi: 10.11896/ cldb. 19080033
12. Huang J., Fan Y., Ouyang X. (2020): Molecular dynamics study on axial mechanical properties of $\mathrm{C}-\mathrm{S}-\mathrm{H}$. Materials Research Express, 7(8), 085011.

13. Hamid S. (1981): The crystal structure of the $11 \AA$ natural tobermorite $\mathrm{Ca}_{2.25}\left[\mathrm{Si}_{3} \mathrm{O}_{7.5}(\mathrm{OH})_{1.5}\right] \cdot 1 \mathrm{H}_{2} \mathrm{O}$. Zeitschriftfür Kristallographie-CrystallineMaterials, 154, 189-198. doi: 10.1524/zkri.1981.154.14.189

14. Hou D., Li Z. (2014): Molecular dynamics study of water and ions transported during the nanopore calcium silicate phase: case study of jennite. Journal of Materials in Civil Engineering, 26(5), 930-940. doi: 10.1061/(ASCE) MT.1943-5533.0000886

15. Chen J., Thomas J., Taylor H., Jennings H. (2004): Solubility and structure of calcium silicate hydrate. Cement and Concrete Research, 34(9), 1499-1519. doi: 10.1016/j. cemconres.2004.04.034

16. Murray S., Subramani V., Selvam R., et al. (2010): Molecular dynamics to understand the mechanical behavior of cement paste. Transportation Research Record: Journal of the Transportation Research Board, 2142(1), 75-82. doi: 10.3141/2142-11

17. Mishra R., Mohamed A., Geissbuhler D., et al. (2017): A force field database for cementitious materials including validations, applications and opportunities. Cement and Concrete Research, 102, 68-89. doi: 10.1016/j.cemconres. 2017.09.003

18. Kirkpatrick R., Kalinichev A., Wang J., Hou X., Amonette J. (2005): Molecular modeling of the vibrational spectra of interlayer and surface species of layered double hydroxides, in: The Application of Vibrational Spectroscopy to Clay Minerals and Layered Double Hydroxides. The Clay Mineral Society, pp. 239-285. doi: 10.1346/CMS-WLS-13

19. Cygan R. T., Liang J. J., Kalinichev A. G. (2004) : Molecular models of hydroxide, oxyhydroxide, and clay phases and the development of a general force field. The Journal of Physical Chemistry B, 108(4), 1255-1266. doi: 10.1021/ jp0363287

20. Shahriyari R., Khosravi A., Ahmadzadeh A. (2013): Nanoscale simulation of Na-Montmorillonite hydrate under basin conditions, application of CLAYFF force field in parallel GCMC. Molecular Physics, 111(20), 3156-3167. doi:10.1080/00268976.2013.772666

21. Rotenberg B., Patel A., Chandler D. (2011): Molecular explanation for why talc surfaces can be both hydrophilic and hydrophobic. Journal of the American Chemical Society, 133(50), 20521-20527. doi:10.1021/ja208687a

22. Solc R., Gerzabek M., Lischka H., Tunega D. (2011): Wettability of kaolinite (001) surfaces-Molecular dynamic study. Geoderma, 169, 47-54. doi: 10.1016/j.geoderma. 2011.02.004

23. Ji Q., Pellenq J., Vliet K. (2012): Comparison of computational water models for simulation of calcium-silicatehydrate. Computational Material Science, 53(1), 234-240. doi: 10.1016/j.commatsci.2011.08.024

24. Kalinichev A., Wang J., Kirkpatrick R. (2007): Molecular dynamics modeling of the structure, dynamics and energetics of mineral-water interfaces: Application to cement materials. Cement and Concrete Research, 37(3), 337-347. doi: 10.1016/j.cemconres.2006.07.004

25. Zhou J., Liang Y. (2020): Reactive molecular dynamics simulation on the structure characteristics and tensile properties of $\mathrm{C}-\mathrm{S}-\mathrm{H}$ at various temperatures and strain rates. Molecular Simulation, 46(15), 1181-1190. doi: 10.1080/ 08927022.2020 .1807543 
26. Meral C., Benmore C., Monteiro P. (2011): Study of disorder and nanocrystallinity in $\mathrm{C}-\mathrm{S}-\mathrm{H}$, supplementary cementitious materials and geopolymers using pair distribution function analysis. Cement and Concrete Research, 41(7), 696-710. doi: 10.1016/j.cemconres.2011.03.027

27. Zhu X., Qian C., He B., et al.(2020): Experimental study on the stability of $\mathrm{C}-\mathrm{S}-\mathrm{H}$ nanostructures with varying bulk $\mathrm{CaO} / \mathrm{SiO}_{2}$ ratios under cryogenic attack. Cement and Concrete Research, 135, 106114. doi: 10.1016/j.cemconres. 2020.106114

28. Richardson I.G. (2014): Model structures for C-(A)-S-H(I). Acta Crystallographica Section B, 70(6), 903-923. doi: $10.1107 / \mathrm{S} 2052520614021982$
29. Gaboreau S., Grangeon S., Claret F., et al. (2020): Hydration properties and interlayer organizationin synthetic CSH. Langmuir, 36(32),9449-9464. doi: 10.1021/acs.langmuir. 0c01335

30. Fu X., Shen W., Yao T. (2006). Physical Chemistry. Higher Education Press, China.

31. Zhou Y., Hou D.,J iang J., et al. (2017): Experimental and molecular dynamics studies on the transport and adsorption of chloride ions in the nano-pores of calcium silicate phase: The influence of calcium to silicate ratios. Microporous \& Mesoporous Materials, 255, 23-35. doi: 10.1016/j.micromeso.2017.07.024 